\title{
DESIGN AND APPLICATION OF A QUANTITATIVE FORECAST MODEL FOR DETERMINATION OF THE PROPERTIES OF ALUMINUM ALLOYS USED IN DIE CASTING
}

\author{
Cristopher Antonio Muñoz-Ibáñez $(\mathbb{D})$ and Mariel Alfaro-Ponce $\mathbb{C}$ \\ Escuela Superior de Tizayuca, Universidad Autónoma del Estado de Hidalgo, Km. 2.5 de la Carretera Federal Tizayuca- \\ Pachuca, 43816 Tizayuca, Hgo, Mexico \\ Gilberto Perez-Lechuga (1) \\ Colegio de Posgrado, Universidad Autónoma del Estado de Hidalgo, Carr. a Pachuca 4, Colosio, 42084 Mineral de la \\ Reforma, Hgo, Mexico \\ Jose Alfredo Pescador-Rojas (i) \\ Escuela Superior de Apan, Universidad Autónoma del Estado de Hidalgo, Carretera Apan-Calpulalpan Km.8, \\ Col.Chimalpa, 43920 Apan, Hgo, Mexico
}

Copyright $\odot 2018$ The Author(s)

https://doi.org/10.1007/s40962-018-0231-6

Abstract

\begin{abstract}
In the field of casting aluminum alloys, integrated computational materials engineering (ICME) is a relatively emerging trend. Through mathematical modeling, new alloys that meet the requirements of the industry can be generated. However, the development of a new alloy with particular attributes is still an enormous challenge; testing the individual possible combinations is numerous. There are several dozen different metals, and even if the alloys are binary, there are many alternatives. This makes ICME a suitable and practical tool to predict the behavior of new alloys. In this paper, the presented model when used to
\end{abstract}

characterize the behavior of alloys shows a reliability level superior to $90 \%$. The mathematical description of the model is also presented. It can be used as a reliable tool for the selection of the desired elements in its composition letting the selection of the most important properties according to the industrial needs and standards.

Keywords: die casting, aluminum alloy, quantitative forecast model, integrated computational materials engineering

\section{Introduction}

Today, there are large quantities of aluminum parts manufactured using the die casting process, ${ }^{25}$ and integrated into the different activities of the production of automobiles, ${ }^{19}$ airplanes, ${ }^{10}$ electrical and electronic components, ${ }^{35}$ and other applications. ${ }^{14}$ Its usefulness is so varied and complex that it makes die casting an important industry within the economic activities of the worldwide metals sector.

Within this diversity of applications of the die casting industry, ${ }^{15}$ the use of alloyed metals is imperative since the particular properties of each component will depend in large part on them. When alloy metals first existed adding elements to improve performance according to the intended application was not a practice. ${ }^{24}$ Nowadays, "materials design" activities are carried out, to obtain the ones that best adapt to the specific requirements of individual applications. Initially, this development was the result of accidental discoveries derived from the mixing of metals. That situation changed radically during the last decades, making this activity a systematized process. ${ }^{39}$

However, the development of a new alloy with particular attributes is still an enormous challenge $;^{9}$ the possible combinations for individual testing are numerous. There are several dozen different metals, and even if the alloys are binary, there are too many alternatives and the proportions of each alloying element can vary. ${ }^{33}$ As a result, 
the scientific community developed integrated computational materials engineering (ICME) which uncovers alloy with certain characteristics. By calculating the specific properties needed, promising alloys can be generated. It can also involve a search based upon practical considerations, for example, directed at more cost-effective solutions and excluding the more expensive alloys. ${ }^{18}$

This approximation identified several superalloys that were already used (found by the expensive trial-and-error method). New alloys have also emerged, which can be tested experimentally rather than rehearsed with the full range of possibilities. In that way, ICME can: "significantly reduce the number of tests required for the development of new alloys." 1 In the field of aluminum alloys, ICME has been intensively employed and new studies are emerging with promising alloys. Engineers of the Marshall Space Flight Center (through computer modeling) developed a new high-strength aluminum-silicon alloy that promises to help reduce engine emissions and improve mileage achieved with the same amount of gasoline, in cars, boats and recreational vehicles. This type of material wears better and exhibits a significant resistance to temperatures between 260 and $370{ }^{\circ} \mathrm{C}$. When tested at $315^{\circ} \mathrm{C}$, it is three to four times more resistant than conventional aluminum alloys and can be produced at a price of half a dollar per kilogram. ${ }^{11}$

In other studies, alloys $8011^{34}$ and $3003,{ }^{13}$ usually manufactured in Venezuela for forming and rolling processes, are adjusted by the Ramberg-Osgood and Rasmussen equations, which initially consider factors such as nominal stress and strain. In addition, modulus of elasticity of the material and the test stress for the deformation, according to the offset method, ${ }^{26}$ were considered to extend the equation and consider factors such as ultimate deformation and ultimate stress, which can be determined with $93 \%$ of elastoplastic behavior of the alloy, ${ }^{8,37}$

ICME developed models based on the control of a particular property; within these, one of the most frequently analyzed properties is the hot crack, which occurs in the solidification process of the material once it has been injected into the permanent mold. Katgerman ${ }^{17}$ developed a mathematical model to calculate the hot fracture trends of the die casting process. The Feurer model, ${ }^{32}$ which considers the time taken by the process for the solidification of the material and the appearance of the hot fracture, establishes that the hot fracture is a trend that can be calculated.

When developing a model, the properties play the most important factor. One of these is the solidification which is the transformation of the material from liquid to solid state. ${ }^{38}$ This metallurgical stage plays an important role in the die casting processes. ${ }^{6}$ On the other hand, its simulation by means of computer programs for the solidification of metals and their alloys results in a complex phenomenon, ${ }^{7,31}$ so the assumptions and limitations used in their constriction are vital, 6,27 Some of these factors considered in the die casting processes are, for example, the permanent mold design, which has a close relationship with the gases trapped inside the mold during the solidification stage. $^{30}$ Another property considered is the pressure applied during the die casting process, which reduces the entrained gases and forms a tight contact between the casting and mold, ${ }^{3,22}$ Finally, the solidification time of the material helps release the heat at a faster rate and produces fine-grained structure castings. ${ }^{20}$

The analysis of all these described models above establishes how complex and challenging is the simulation and control of the mechanical ${ }^{4}$ and physical properties of the materials, which is making the engineer's task complex when deciding what type of alloy or material should be used during the design of the product and manufacturing process. ${ }^{36}$ Taking these factors into account, a unique mathematical model, ${ }^{12,40}$ which evaluates the physical, mechanical and particular characteristics of the aluminum alloy, will be a cutting-edge tool improving time, quality and cost.

In this paper, the formulation of a model that takes into account the chemical composition of the alloy and how it modifies the behavior of the material properties is developed. Also, it is important to mention that the present model is a tool that gave a fast and accurate approximation of the behavior of die casting alloys according to the characteristics identified by the North American Die Casting Association (NADCA). ${ }^{23}$ The paper is organized as follows; "Methods and Materials" Section presents the elements considered for the model and their chemical and physical properties. The mathematical construction of the model is also described in detail for each property. "Selection of Base Alloys for the Mathematical Model, Chemical, Physical, Mechanical and Specific Properties for Die Casting" Section contains the results achieved by the proposed model, the error and accuracy for both mechanical and physical properties. Finally, "Conclusions and Discussion" Section presents the conclusions and discussions of the results achieved by the presented model.

\section{Methods and Materials}

In the development of the model, it is important to have a statistical base with the purpose of reducing the variations in the forecasts, and to be able to fulfill the specific requirements of a sector or class of product. The model takes as a base for calculation alloys that are typical of the sector or those that the companies consider significant for the forecast. In this study, die-castable alloys of the Aluminum Association were employed. They are described in "Selection of Base Alloys for the Mathematical Model, Chemical, Physical, Mechanical and Specific Properties for Die Casting" Section, in order to achieve an adjustment of 
the curves that will be used in a forecast of the characteristics of the alloy.

This forecast has the main objective of determining the characteristics of the materials, taking as input variables the correlation between the chemical composition of the alloy and the characteristic to be analyzed. It is important to note that these relations can change depending on the type of base alloys analyzed and the relationships which are obtained. Because the effects of the component materials of the alloys such as silicon, copper, magnesium, iron, manganese and zinc can vary drastically between one percentage point and another, a practical example is what happens with silicon ( $\mathrm{Si}$ ), which is an element that improves die-filling capacity (DFC) and increases the fluidity and resistance to misruns. With the above, the content of silicon must be according to the speed of solidification of the process to avoid porosity by contraction. Then, in emptyings by gravity in sand, or lost wax, the percentage is between 5 and 7\%; for permanent casting 7-9\% and for die casting, from 8 to $12 \%$. According to these margins and specific processes, the correlations can change from one margin to another or from one process to another, due in large part to the wide margin that exists for the formulation of the alloy. To reduce this type of error, it is convenient to form the basis of the model of a family of alloys that have similar characteristics in the process that is desired and evaluate its application. In this way, rapid forecast models for die-castable alloys, rapid forecast models for gravity casting alloys or rapid forecast models for permanent cast casting alloys can be generated and each of them will conform to the specific conditions of the process or the product that is being analyzed.

The procedure described above is currently used in spectrometry equipment, which has a general calibration that takes into account a wide range of alloys. However, in the specific industry requirements it is advisable to use standard calibrations to ensure that the process and the specifications of the process are achieved by the product in a specific way and with the same criteria.

\section{Model Construction}

The model will perform the rapid forecast for the different mechanical, physical and specific properties of the sector to be analyzed. To carry out this process, first it will be necessary to select the alloys and their chemical, mechanical, physical and specific characteristics, which will serve as a foundation for model adjustment. These alloys will be described in "Selection of Base Alloys for the Mathematical Model, Chemical, Physical, Mechanical and Specific Properties for Die Casting" Section of this article.

Table 1. Pearson Correlation Index According to the Properties

\begin{tabular}{|c|c|c|c|c|c|c|c|c|}
\hline Properties & $\mathrm{Si}$ & $\mathrm{Fe}$ & $\mathrm{Cu}$ & $\mathrm{Mg}$ & $\mathrm{Mn}$ & $\mathrm{Ni}$ & $\mathrm{Zn}$ & Sn \\
\hline UTS & 0.301 & -0.468 & 0.521 & 0.097 & 0.533 & -0.194 & 0.493 & 0.410 \\
\hline YS & 0.327 & -0.314 & 0.462 & 0.320 & 0.367 & -0.729 & 0.086 & -0.126 \\
\hline$E$ & -0.626 & 0.300 & -0.341 & 0.180 & -0.282 & -0.142 & -0.291 & -0.253 \\
\hline $\mathrm{H}$ & 0.637 & -0.383 & 0.647 & 0.003 & 0.460 & -0.64 & 0.146 & -0.13 \\
\hline SS & 0.003 & -0.291 & 0.413 & 0.367 & 0.458 & -0.344 & 0.415 & 0.458 \\
\hline IS & -0.982 & 0.240 & -0.953 & 0.999 & -1 & -0.821 & -1 & -0.5 \\
\hline FS & 0.114 & -0.148 & 0.565 & 0.196 & 0.663 & -0.428 & 0.603 & 0.325 \\
\hline YM & 0.812 & -0.377 & 0.608 & 0.508 & 0.377 & -0.882 & -0.02 & -0.386 \\
\hline D & 0.444 & -0.333 & 0.791 & -0.596 & 0.800 & 0.203 & 0.839 & 0.612 \\
\hline MR & -0.240 & 0.487 & -0.522 & 0.122 & -0.662 & 0.010 & -0.752 & -0.501 \\
\hline CTE & -0.927 & 0.320 & -0.499 & 0.614 & -0.324 & 0.156 & -0.122 & 0.253 \\
\hline TC & 0.299 & 0.190 & -0.241 & -0.292 & -0.435 & -0.027 & -0.588 & -0.628 \\
\hline EC & -0.024 & 0.522 & -0.563 & -0.268 & -0.681 & 0.348 & -0.668 & -0.485 \\
\hline $\mathrm{RHC}$ & -0.394 & 0.104 & 0.122 & 0.712 & 0.075 & -0.733 & -0.145 & -0.111 \\
\hline PT & -0.426 & 0.071 & 0.021 & 0.748 & 0.028 & -0.804 & -0.192 & -0.255 \\
\hline ASD & -0.718 & 0.264 & -0.437 & 0.737 & -0.361 & -0.477 & -0.429 & -0.355 \\
\hline CR & 0.370 & -0.360 & 0.860 & -0.488 & 0.862 & 0.238 & 0.908 & 0.818 \\
\hline MEQ & 0.261 & 0.183 & -0.015 & -0.157 & -0.260 & -0.11 & -0.454 & -0.384 \\
\hline PEQ & 0.763 & -0.094 & 0.164 & -0.677 & -0.043 & 0.176 & -0.14 & -0.295 \\
\hline$A$ & 0.912 & -0.333 & 0.379 & -0.610 & 0.175 & 0.123 & 0.082 & -0.079 \\
\hline
\end{tabular}


Once the selection of the base alloys is made, it will be necessary to establish the correspondence between the chemical element and the properties to be analyzed, and this correlation can be changed according to the selected base of alloys. To establish these relationships, the Pearson Correlation Index will be used as given in Eqn. 1.

$$
r=\frac{n \sum_{i=1}^{n} x_{i} y_{i}-\sum_{i=1}^{n} x_{i} \sum_{i=1}^{n} y_{i}}{\sqrt{\left[n \sum_{i=1}^{n} x_{i}^{2}-\left(\sum_{i=1}^{n} x_{i}\right)^{2}\right]\left[n \sum_{i=1}^{n} y_{i}^{2}-\left(\sum_{i=1}^{n} y_{i}\right)^{2}\right]}}
$$

Eqn. 1

As shown, $r$ is the Pearson Correlation Coefficient (PCC) that comes from comparing the chemical element $x_{i}$ with the mechanical, physical or specific property $y_{i}$.

With the correlation obtained (Table 1), it is possible to select the element or elements that have a greater

Table 2. Chemical Properties of Die-Castable Alloys According to the Aluminum Association (AA)

\begin{tabular}{lrlllllll}
\hline Name & \multicolumn{1}{l}{$\mathrm{Si}$} & $\mathrm{Fe}$ & $\mathrm{Cu}$ & $\mathrm{Mg}$ & $\mathrm{Mn}$ & $\mathrm{Ni}$ & $\mathrm{Zn}$ & $\mathrm{Sn}$ \\
\hline 360.0 & 9.50 & 2.00 & 0.60 & 0.50 & 0.35 & 0.50 & 0.50 & 0.15 \\
380.0 & 8.50 & 2.00 & 3.50 & 0.30 & 0.50 & 0.50 & 3.00 & 0.35 \\
383.0 & 10.50 & 1.30 & 2.50 & 0.10 & 0.50 & 0.30 & 3.00 & 0.15 \\
384.0 & 11.00 & 1.30 & 3.80 & 0.10 & 0.50 & 0.50 & 3.00 & 0.35 \\
413.0 & 12.00 & 2.00 & 1.00 & 0.10 & 0.35 & 0.50 & 0.50 & 0.15 \\
518.0 & 0.35 & 1.80 & 0.25 & 8.00 & 0.35 & 0.15 & 0.15 & 0.15 \\
A360.0 & 9.50 & 1.30 & 0.60 & 0.50 & 0.35 & 0.50 & 0.50 & 0.15 \\
A380.0 & 8.50 & 1.30 & 3.50 & 0.30 & 0.50 & 0.50 & 3.00 & 0.35 \\
A413.0 & 12.00 & 1.30 & 1.00 & 0.10 & 0.35 & 0.50 & 0.50 & 0.15 \\
B390.0 & 17.00 & 1.30 & 4.50 & 0.55 & 0.50 & 0.10 & 1.50 & 0.10 \\
C443.0 & 5.00 & 2.00 & 0.60 & 0.10 & 0.35 & 0.50 & 0.50 & 0.15 \\
\hline
\end{tabular}

correlation with the mechanical, physical or specific property that is analyzed. In this way and by means of test runs, it can be established which type of curve best fits the property according to the base of alloys used to make the base of the model. This process is described in "Example of the Model" Section, where the model is run with the base of alloys described in "Selection of Base Alloys for the Mathematical Model, Chemical, Physical, Mechanical and Specific Properties for Die Casting" Section.

\section{Selection of Base Alloys for the Mathematical Model, Chemical, Physical, Mechanical and Specific Properties for Die Casting}

Aluminum alloys consist of six elements: silicon ( $\mathrm{Si}$ ), copper $(\mathrm{Cu})$, magnesium $(\mathrm{Mg})$, iron $(\mathrm{Fe})$, manganese $(\mathrm{Mn})$ and zinc $(\mathrm{Zn})$ in an aluminum matrix. ${ }^{5}$ Each of the above elements affects the properties of the alloy, both independently and in its interaction with the other elements. According to the North American Die Casting Association (NADCA), the aluminum alloys most commonly used commercially in forming parts by the die casting process $\operatorname{are}^{23}$ :

- Alloy A380 (ANSI/AA A380.0) It is by far the most widely used alloy for die casting, offering the best combination of properties and ease of processing. It can be used in a wide variety of applications including, but not limited to: electronic and communications equipment, automotive components, transmission and gear housings, trims and hand tools.

- Alloy 383 (ANSI/AA 383.0) and Alloy 384 (ANSI/ $A A 384.0)$ They are alternative alloys to the AA 380.0 for application in parts with intricate profiles; in addition to that, the alloy AA 383.0 offers better resistance to hot fracture.

Table 3. Physical Properties of Die-Castable Alloys According to NADCA A-3 ${ }^{23}$

\begin{tabular}{|c|c|c|c|c|c|}
\hline Alloy & $\begin{array}{l}\text { Density } \\
(\mathrm{g} / \mathrm{cm} 3)\end{array}$ & $\begin{array}{l}\text { Melting } \\
\text { range }\left({ }^{\circ} \mathrm{C}\right)\end{array}$ & $\begin{array}{l}\text { Coefficient of thermal } \\
\text { expansion }\left(\mu \mathrm{m} / \mathrm{m}^{\circ} \mathrm{K}\right)\end{array}$ & $\begin{array}{l}\text { Thermal conductivity } \\
\left(\mathrm{W} / \mathrm{m}^{\circ} \mathrm{K}\right)\end{array}$ & $\begin{array}{l}\text { Electrical conductivity } \\
\text { (\%IACS) }\end{array}$ \\
\hline 360.0 & 2.63 & 576.50 & 21.00 & 113.00 & 30.00 \\
\hline A360.0 & 2.63 & 576.50 & 21.00 & 113.00 & 29.00 \\
\hline 380.0 & 2.74 & 567.50 & 22.00 & 96.20 & 27.00 \\
\hline A380.0 & 2.71 & 567.50 & 21.80 & 96.20 & 23.00 \\
\hline 383.0 & 2.74 & 549.00 & 21.10 & 96.20 & 23.00 \\
\hline 384.0 & 2.82 & 549.00 & 21.00 & 96.20 & 22.00 \\
\hline B390.0 & 2.71 & 580.00 & 18.00 & 134.00 & 27.00 \\
\hline 413.0 & 2.66 & 578.00 & 20.40 & 121.00 & 31.00 \\
\hline A413.0 & 2.66 & 578.00 & 21.60 & 121.00 & 31.00 \\
\hline C443.0 & 2.69 & 603.00 & 22.00 & 142.00 & 37.00 \\
\hline 518.0 & 2.57 & 578.00 & 24.10 & 96.20 & 24.00 \\
\hline
\end{tabular}


- Alloy 360 (ANSI/AA A360.0) This alloy offers high corrosion resistance and high resistance to hot fracture. However, its low fluidity makes it difficult to process.

- Alloy 43 (ANSI/AA C443.0) It is the alloy with the highest ductility in the aluminum family, although its use is not very widespread because it is tough to process. It offers moderate corrosion resistance and is often used in marine grade applications.

- Alloy A13 (ANSI/AA A413.0) It provides excellent compaction, making it a good choice for the manufacture of hydraulic cylinders and pressure vessels. Its process characteristics make it suitable for complex profile components.

- Alloy 390 (ANSI/AA B390.0) It is developed specifically for the manufacture of automotive engine blocks, with excellent wear resistance but poor ductility. It is used for the production of valve bodies and uncured piston cylinders.

- Alloy 518 (ANSI/AA 518.0) It provides a good combination of toughness, ductility, corrosion resistance and finishing qualities, but is harder to inject.

The chemical composition of the alloys described is shown in Table 2, which considers the main alloying elements in the formulation of the alloy. It will be necessary to establish a relationship between these and the property that is desired to be substantially improved.

On the other hand, NADCA A-3 lists the mechanical and physical properties (see Tables 3,4 ) and the specific ones according to the needs of the die casting industry. These properties are essential for the success of the process, as well as for obtaining quality products that satisfy and surpass the expectations of the diverse clients of the industry. Some of these component and service performance properties include resistance to elevated temperature fracture, pressure tightness, corrosion resistance, ability to fill complex geometries that are nonmoldable and thin wall sections. These and other properties are critical considerations during the formulation of alloys intended for practical use in the die casting industry (Table 4).

\section{Example of the Model}

The model will predict the main physical, mechanical and precise characteristics of die casting using the direct relationship between the features to be controlled and the constituent chemical elements of the alloy, taking into account the element or elements whose content directly affects the characteristic or characteristics in the monitoring of the alloy. The elements will be selected according to the existing degree of correlation as established in Table 1. The element or elements will be selected according to their weight and adjustment to the model.

The construction of the model that will be developed in the subsections "Ultimate Tensile Strength (UTS), Yield Strength (YS) and Elongation (E)" is based on the best adjustment of the desired characteristic, whether mechanical, physical or specific. These characteristics are the consequence of the elements that have the greatest impact on the mathematical model, as a result, tables describing these values were developed. The metallurgical model will develop the following specific properties as important in the casting process (Table 5).

\section{Ultimate Tensile Strength (UTS)}

This property assumes that the failure or fracture of the material occurs when the maximum standard tensile at a point reaches the equivalent of the value of a critical

Table 4. Mechanical Properties of Die-Castable Alloys According to NADCA A-3 ${ }^{23}$

\begin{tabular}{lllllllll}
\hline Alloy & $\begin{array}{l}\text { Ultimate tensile } \\
\text { strength }(\mathrm{MPa})\end{array}$ & $\begin{array}{l}\text { Yield } \\
\text { strength } \\
(\mathrm{MPa})\end{array}$ & $\begin{array}{l}\text { Elongation } \\
(\% / 51 \mathrm{~mm})\end{array}$ & $\begin{array}{l}\text { Hardness } \\
(\mathrm{BHN})\end{array}$ & $\begin{array}{l}\text { Shear } \\
\text { strength } \\
(\mathrm{MPa})\end{array}$ & $\begin{array}{l}\text { Impact } \\
\text { strength }(\mathrm{J})\end{array}$ & $\begin{array}{l}\text { Fatigue } \\
\text { strength } \\
(\mathrm{MPa})\end{array}$ & $\begin{array}{l}\text { Young } \\
\text { Modulus } \\
(\mathrm{GPa})\end{array}$ \\
\hline 360.0 & 303.00 & 170.00 & 2.50 & 75.00 & 190.00 & - & 140.00 & 71.00 \\
A360.0 & 317.00 & 170.00 & 3.50 & 75.00 & 180.00 & & 120.00 & 71.00 \\
380.0 & 317.00 & 160.00 & 3.50 & 80.00 & 190.00 & 4.00 & 140.00 & 71.00 \\
A380.0 & 324.00 & 160.00 & 3.50 & 80.00 & 190.00 & & 140.00 & 71.00 \\
383.0 & 310.00 & 150.00 & 3.50 & 75.00 & - & 4.00 & 145.00 & 71.00 \\
384.0 & 330.00 & 165.00 & 2.60 & 85.00 & 200.00 & - & 140.00 & - \\
B390.0 & 317.00 & 250.00 & - & 120.00 & - & - & 140.00 & 81.30 \\
413.0 & 300.00 & 140.00 & 2.50 & 80.00 & 170.00 & - & 130.00 & 71.00 \\
A413.0 & 290.00 & 130.00 & 3.50 & 80.00 & 170.00 & - & 130.00 & - \\
C443.0 & 228.00 & 97.00 & 9.00 & 65.00 & 130.00 & - & 120.00 & 71.00 \\
518.0 & 310.00 & 193.00 & 5.00 & 80.00 & 200.00 & 9.00 & 140.00 & - \\
\hline
\end{tabular}


Table 5. Specific Properties for Die Casting of NADCA A-3 Die-Castable Alloys, Where 1 is More Desirable and 5 Less Desirable ${ }^{23}$

\begin{tabular}{lllllllll}
\hline Alloy & RHC & PT & ASD & CR & ME\&E & PE\&Q & EE\& Q & A \\
\hline 360.0 & 1 & 2 & 2 & 2 & 3 & 3 & 2 & 3 \\
A360.0 & 1 & 2 & 2 & 2 & 3 & 3 & 2 & 3 \\
380.0 & 2 & 2 & 1 & 4 & 3 & 3 & 1 & 3 \\
A380.0 & 2 & 2 & 1 & 4 & 3 & 3 & 1 & 3 \\
383.0 & 1 & 2 & 2 & 3 & 2 & 3 & 1 & 3 \\
384.0 & 2 & 2 & 2 & 5 & 3 & 3 & 2 & 4 \\
B390.0 & 4 & 4 & 2 & 3 & 5 & 5 & 3 & 5 \\
413.0 & 1 & 1 & 1 & 2 & 4 & 5 & 3 & 5 \\
A413.0 & 1 & 1 & 1 & 2 & 4 & 5 & 3 & 5 \\
C443.0 & 3 & 3 & 4 & 2 & 5 & 4 & 2 & 2 \\
518.0 & 5 & 5 & 5 & 1 & 3 & 1 & 5 & 1 \\
\hline
\end{tabular}

RHC Resistance to hot cracking, $P T$ pressure tightness, $D F C$ diefilling capacity, $E E \& Q$ electroplating ease \& quality, $C R$ corrosion resistance, ME\&Q machining ease \& quality , $A S D$ anti-soldering to the die, $P E \& Q$ polishing ease \& quality, $A$ anodizing (appearance), COPC chemical oxide protective casting, SET strength at elevated temperature

tensile. ${ }^{21}$ The most significant element for this property is manganese $(\mathrm{Mn})$ with a PPC of 0.53 , followed by copper $(\mathrm{Cu})$ and zinc $(\mathrm{Zn})$ with 0.52 and 0.49 , respectively; the property is modeled by Eqn. 2 shown:

$\mathrm{UTS}=\beta_{0}+\beta_{1} X_{1}+\beta_{2} X_{2}+\beta_{3} X_{3}$

Eqn. 2

where $X_{1}$ is the percentage of manganese in the alloy, $X_{2}$ is that of copper and $X_{3}$ is that of zinc. The values of $\beta_{0}, \beta_{1}$, $\beta_{2}$ and $\beta_{3}$ are obtained after numerically treating the alloys described in Table 4. This model can be applied to the following properties

- Young's Module (YM) Also known as longitudinal modulus of elasticity is a parameter that characterizes the behavior of an elastic material, according to the direction in which a force is applied.

- Coefficient of thermal expansion (CTE) Thermal expansion is the increase in the volume of a material as its temperature increases; it is often expressed as a fractional change in measurements per unit change in temperature. When the material is solid, thermal expansion is described as a change in length, height or thickness.

The values employed for the model application can be seen in Table 6

Yield Strength (YS)

This concept defines effort as the intensity of the distributed forces of the inner component that resists a change in the shape of a body. The most influential element in this
Table 6. Values Employed for the Properties Modeled by Eqn. 2

\begin{tabular}{llllrrrl}
\hline Property & $X_{1}$ & $X_{2}$ & $X_{3}$ & \multicolumn{1}{l}{$\beta_{0}$} & \multicolumn{1}{l}{$\beta_{1}$} & \multicolumn{1}{l}{$\beta_{2}$} & $\beta_{3}$ \\
\hline UTS & $\mathrm{Mn}$ & $\mathrm{Cu}$ & $\mathrm{Zn}$ & 245.57 & 124.47 & 2.90 & 0.54 \\
YM & $\mathrm{Ni}$ & $\mathrm{Si}$ & $\mathrm{Cu}$ & 1.75 & 72.00 & 3.38 & 2.49 \\
CTE & $\mathrm{Si}$ & $\mathrm{Mg}$ & $\mathrm{Cu}$ & 24.47 & -0.34 & -0.039 & 0.0052 \\
\hline
\end{tabular}

property is nickel $(\mathrm{Ni})$, with a $\mathrm{CCP}$ higher than 0.70 ; this property is included in the model using Eqn. 3:

$\mathrm{YS}=\varepsilon_{0}+\varepsilon_{1} X+\varepsilon_{2} X^{2}$

Eqn. 3

where $\mathrm{X}$ is the percentage of nickel required in the alloy, and the values of $\varepsilon_{0}, \varepsilon_{1}$ and $\varepsilon_{2}$ are shown in Table 7 . There are other properties mentioned below for which the model is suitable.

- Hardness $(H)$ The hardness of a material is defined as its resistance to permanent indentation. An excellent hardness usually means that the materials are resistant to scraping and wear. ${ }^{29}$

- Shear strength (SS) It is the internal stress resulting from the tensions parallel to the cross section of a mechanical prism.

Table 7. Values Employed for the Properties Modeled by Eqn. 3

\begin{tabular}{lllrr}
\hline Property & $X \%$ & $\varepsilon_{0}$ & \multicolumn{2}{c}{$\varepsilon_{1}$} \\
\hline YS & $\mathrm{Ni}$ & 327.61 & -995.82 & 1277.82 \\
$\mathrm{H}$ & $\mathrm{Cu}$ & 86.45 & 21.18 & 5.93 \\
$\mathrm{SS}$ & $\mathrm{Mn}$ & $1.02 \mathrm{E}-12$ & 748.57 & -723.81 \\
$\mathrm{IS}$ & $\mathrm{Mn}$ & $2.48 \mathrm{E}-14$ & 67.04 & -118.09 \\
$\mathrm{D}$ & $\mathrm{Zn}$ & 2.57 & 0.14 & -0.029 \\
MR & $\mathrm{Zn}$ & 578.08 & 10.54 & -5.72 \\
TC & $\mathrm{Sn}$ & 190.46 & -682.71 & 1181.14 \\
RHC & $\mathrm{Ni}$ & 7.73 & -33.05 & 41.60 \\
PT & $\mathrm{Ni}$ & 6.40 & -19.31 & 20.46 \\
COPC & $\mathrm{Cu}$ & 1.66 & 1.26 & -0.13 \\
\hline
\end{tabular}

Table 8. Values Employed for the Properties Modeled by Eqn. 4

\begin{tabular}{llrr}
\hline Property & $X \%$ & \multicolumn{1}{c}{$\gamma$} \\
\hline E & Si & 3.90 & -0.44 \\
FS & Mn & 104.33 & 73.33 \\
EC & Mn & 44.17 & -39.55 \\
DFC & Si & 4.91 & -0.29 \\
A & Si & 0.74 & 0.28 \\
\hline
\end{tabular}




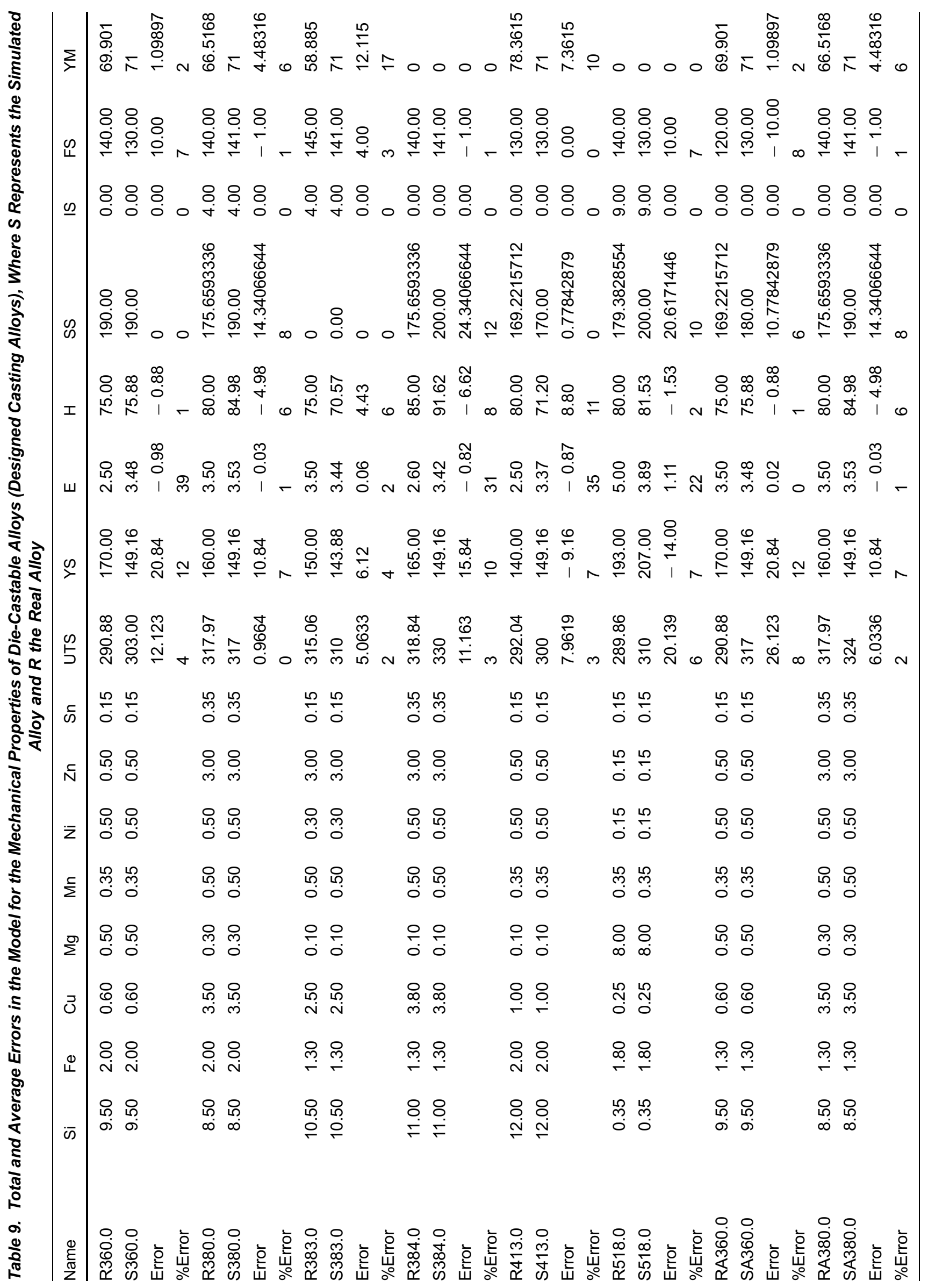




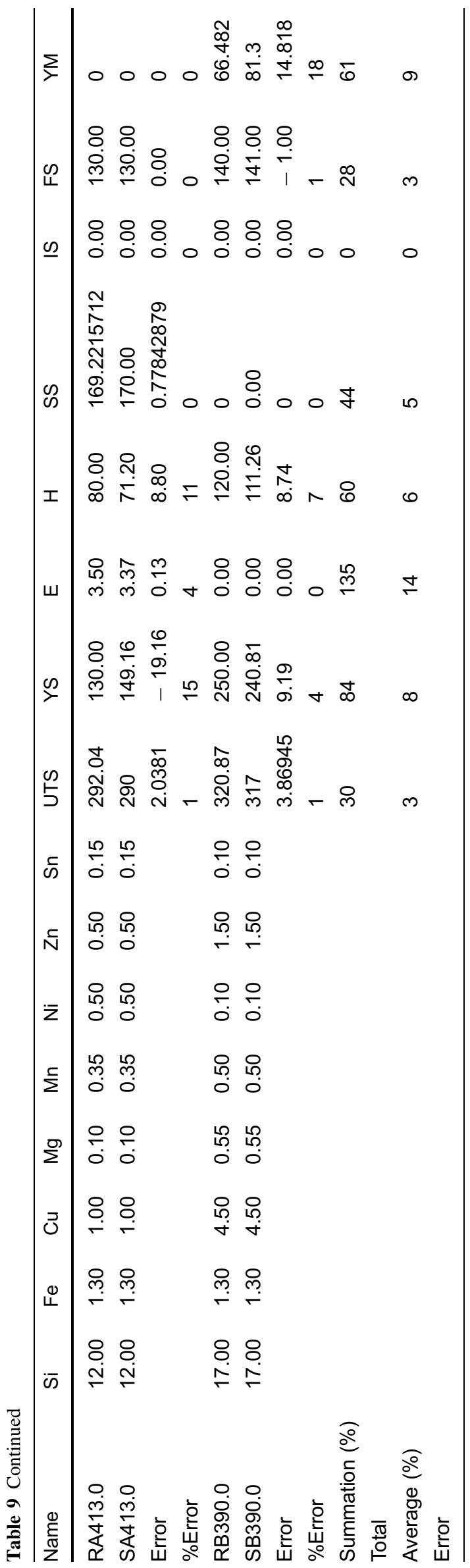

- Impact strength (IS) Impact strength can be defined as the measure of the energy required to break a sample. ${ }^{29}$

- Density (D) The density is a scalar quantity referred to as the amount of mass in a given volume of a substance.

- Melting range (MR) Within the die casting industry, the melting range is an important element to consider, since it depends on the working temperature of the material for subsequent die casting.

- Thermal conductivity (TC) Thermal conductivity indicates the rate at which heat flows through the material.

- Resistance to hot cracking $(R H C)$ The hot cracking is one of the first specific properties of the molten. This can occur as a result of the effect of the thermal contraction characteristic of any fusion process. ${ }^{28}$

- Pressure tightness (PT) It is the resistance of the material to the projection of the force in perpendicular direction per unit of surface.

- Chemical oxide protective coating (COPC) A property that establishes the ability of the material to form, in contact with the environment, a layer of oxide that protects the internal structure of corrosion. $^{23}$

\section{Elongation (E)}

Elongation was defined as the change in the value of a physical quantity on its equilibrium value. ${ }^{16}$ Analyzing the data of the die-castable alloys described above, silicon is established as the dominant element for this property with a CCP higher than 0.60 ; this property is modeled according to Eqn. 3:

$$
E=\gamma+\delta X
$$

Eqn. 4

where $X$ is the percentage of silicon contained in the alloy and $\gamma$ and $\delta$ values for the calculation of the property are shown in Table 8. This model can be employed for the calculation of the following properties.

- Fatigue strength (FS) This property reflects the process of permanent, progressive and localized structural change occurring in a material subject to varying stresses and deformations at some point or points and producing cracks or complete fractures after a sufficient number of fluctuations. ${ }^{2}$

- Electrical conductivity (EC) It is the measure of the ability (or suitability) of a material or substance to allow (or let circulate) the electric current freely.

- Die-filling capacity (DFC) It is the ability of the molten alloy to flow easily into the matrix, filling the thin sections. 
Table 10. Total and Average Errors in the Model for Physical Properties of Die-Castable Alloys (Designed Casting Alloys), Where S Represents the Simulated Alloy and R the Real Alloy

\begin{tabular}{|c|c|c|c|c|c|c|c|c|c|c|c|c|c|}
\hline Name & $\mathrm{Si}$ & $\mathrm{Fe}$ & $\mathrm{Cu}$ & $\mathrm{Mg}$ & $\mathrm{Mn}$ & $\mathrm{Ni}$ & $\mathrm{Zn}$ & Sn & D & MR & CTE & $\mathrm{TC}$ & EC \\
\hline R360.0 & 9.50 & 2.00 & 0.60 & 0.50 & 0.35 & 0.50 & 0.50 & 0.15 & 2.63 & 576.50 & 21.261 & 113.00 & 30.00 \\
\hline S360.0 & 9.50 & 2.00 & 0.60 & 0.50 & 0.35 & 0.50 & 0.50 & 0.15 & 2.64 & 581.93 & 21 & 114.63 & 30.33 \\
\hline Error & & & & & & & & & -0.01 & -5.43 & 0.2607 & -1.63 & -0.33 \\
\hline \%Error & & & & & & & & & 1 & 1 & 1 & 1 & 1 \\
\hline R380.0 & 8.50 & 2.00 & 3.50 & 0.30 & 0.50 & 0.50 & 3.00 & 0.35 & 2.74 & 567.50 & 21.604 & 96.20 & 27.00 \\
\hline S380.0 & 8.50 & 2.00 & 3.50 & 0.30 & 0.50 & 0.50 & 3.00 & 0.35 & 2.75 & 558.20 & 22 & 96.20 & 24.40 \\
\hline Error & & & & & & & & & -0.01 & 9.30 & 0.3959 & 0.00 & 2.60 \\
\hline \%Error & & & & & & & & & 0 & 2 & 2 & 0 & 10 \\
\hline R383.0 & 10.50 & 1.30 & 2.50 & 0.10 & 0.50 & 0.30 & 3.00 & 0.15 & 2.74 & 549.00 & 20.94 & 96.20 & 23.00 \\
\hline S383.0 & 10.50 & 1.30 & 2.50 & 0.10 & 0.50 & 0.30 & 3.00 & 0.15 & 2.75 & 558.20 & 21.1 & 114.63 & 24.40 \\
\hline Error & & & & & & & & & -0.01 & -9.20 & 0.1595 & -18.43 & -1.40 \\
\hline \%Error & & & & & & & & & 0 & 2 & 1 & 19 & 6 \\
\hline R384.0 & 11.00 & 1.30 & 3.80 & 0.10 & 0.50 & 0.50 & 3.00 & 0.35 & 2.82 & 549.00 & 20.773 & 96.20 & 22.00 \\
\hline S384.0 & 11.00 & 1.30 & 3.80 & 0.10 & 0.50 & 0.50 & 3.00 & 0.35 & 2.75 & 558.20 & 21 & 96.20 & 24.40 \\
\hline Error & & & & & & & & & 0.07 & -9.20 & 0.2274 & 0.00 & -2.40 \\
\hline \%Error & & & & & & & & & 2 & 2 & 1 & 0 & 11 \\
\hline R413.0 & 12.00 & 2.00 & 1.00 & 0.10 & 0.35 & 0.50 & 0.50 & 0.15 & 2.66 & 578.00 & 20.437 & 121.00 & 31.00 \\
\hline S413.0 & 12.00 & 2.00 & 1.00 & 0.10 & 0.35 & 0.50 & 0.50 & 0.15 & 2.64 & 581.93 & 20.4 & 114.63 & 30.33 \\
\hline Error & & & & & & & & & 0.02 & -3.93 & 0.0369 & 6.37 & 0.67 \\
\hline \%Error & & & & & & & & & 1 & 1 & 0 & 5 & 2 \\
\hline R518.0 & 0.35 & 1.80 & 0.25 & 8.00 & 0.35 & 0.15 & 0.15 & 0.15 & 2.57 & 578.00 & 24.043 & 96.20 & 24.00 \\
\hline S518.0 & 0.35 & 1.80 & 0.25 & 8.00 & 0.35 & 0.15 & 0.15 & 0.15 & 2.60 & 579.54 & 24.1 & 114.63 & 30.33 \\
\hline Error & & & & & & & & & -0.03 & -1.54 & 0.0575 & -18.43 & -6.33 \\
\hline \%Error & & & & & & & & & 1 & 0 & 0 & 19 & 26 \\
\hline RA380.0 & 8.50 & 1.30 & 3.50 & 0.30 & 0.50 & 0.50 & 3.00 & 0.35 & 2.71 & 567.50 & 21.604 & 96.20 & 23.00 \\
\hline SA380.0 & 8.50 & 1.30 & 3.50 & 0.30 & 0.50 & 0.50 & 3.00 & 0.35 & 2.75 & 558.20 & 21.8 & 96.20 & 24.40 \\
\hline Error & & & & & & & & & -0.04 & 9.30 & 0.1959 & 0.00 & -1.40 \\
\hline \%Error & & & & & & & & & 2 & 2 & 1 & 0 & 6 \\
\hline RA413.0 & 12.00 & 1.30 & 1.00 & 0.10 & 0.35 & 0.50 & 0.50 & 0.15 & 2.66 & 578.00 & 20.437 & 121.00 & 31.00 \\
\hline SA413.0 & 12.00 & 1.30 & 1.00 & 0.10 & 0.35 & 0.50 & 0.50 & 0.15 & 2.64 & 581.93 & 21.6 & 114.63 & 30.33 \\
\hline Error & & & & & & & & & 0.02 & -3.93 & 1.1631 & 6.37 & 0.67 \\
\hline \%Error & & & & & & & & & 1 & 1 & 5 & 5 & 2 \\
\hline RB390.0 & 17.00 & 1.30 & 4.50 & 0.55 & 0.50 & 0.10 & 1.50 & 0.10 & 2.71 & 580.00 & 18.741 & 134.00 & 27.00 \\
\hline SB390.0 & 17.00 & 1.30 & 4.50 & 0.55 & 0.50 & 0.10 & 1.50 & 0.10 & 2.73 & 581.02 & 18 & 134.00 & 24.40 \\
\hline Error & & & & & & & & & -0.02 & -1.02 & 0.7411 & 0.00 & 2.60 \\
\hline \%Error & & & & & & & & & 1 & 0 & 4 & 0 & 10 \\
\hline Summation (\%) & & & & & & & & & 9 & 10 & 17 & 52 & 79 \\
\hline \multicolumn{14}{|l|}{ Total } \\
\hline Average (\%) & & & & & & & & & 1 & 1 & 2 & 5 & 8 \\
\hline Error & & & & & & & & & & & & & \\
\hline
\end{tabular}




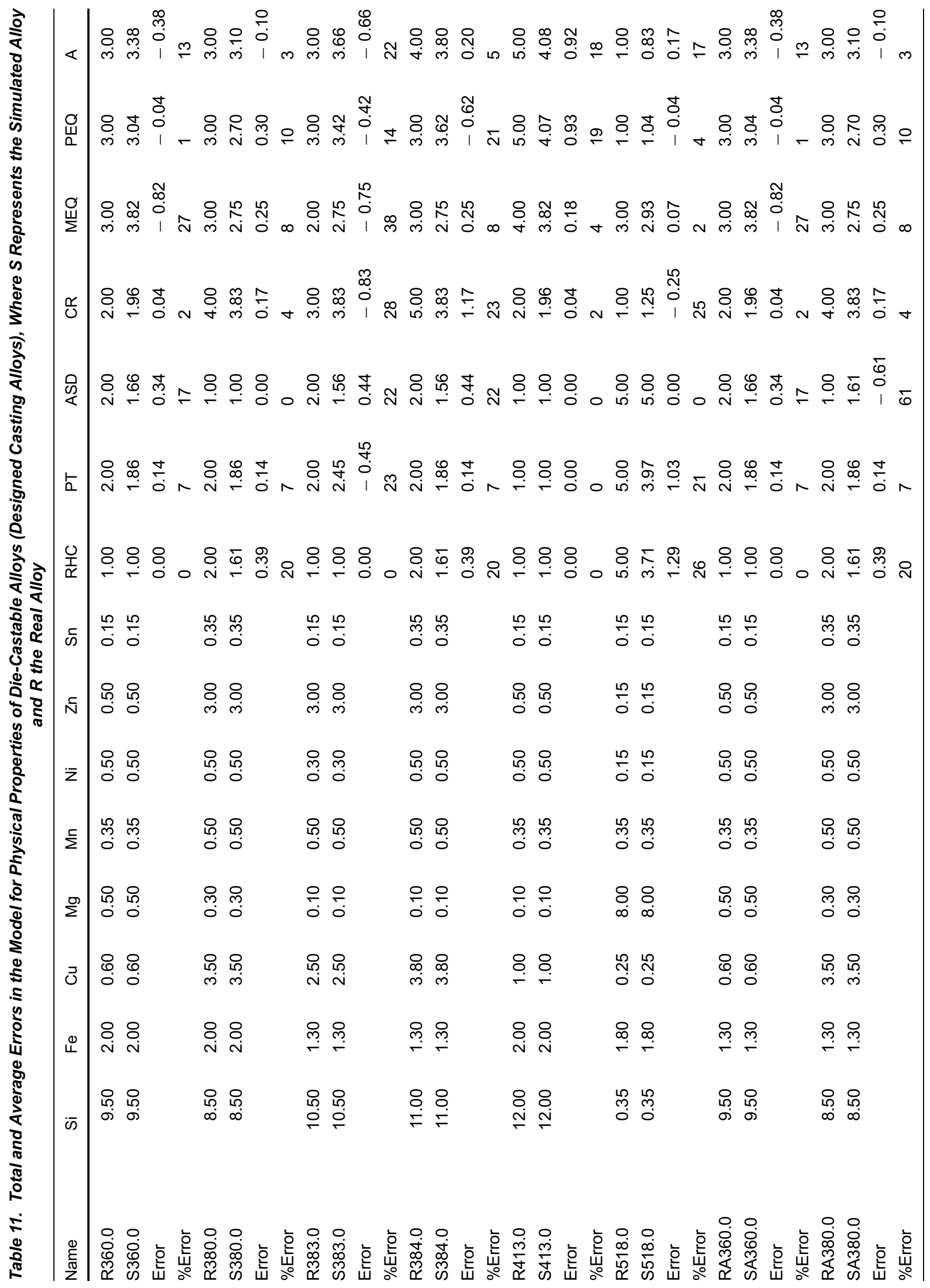




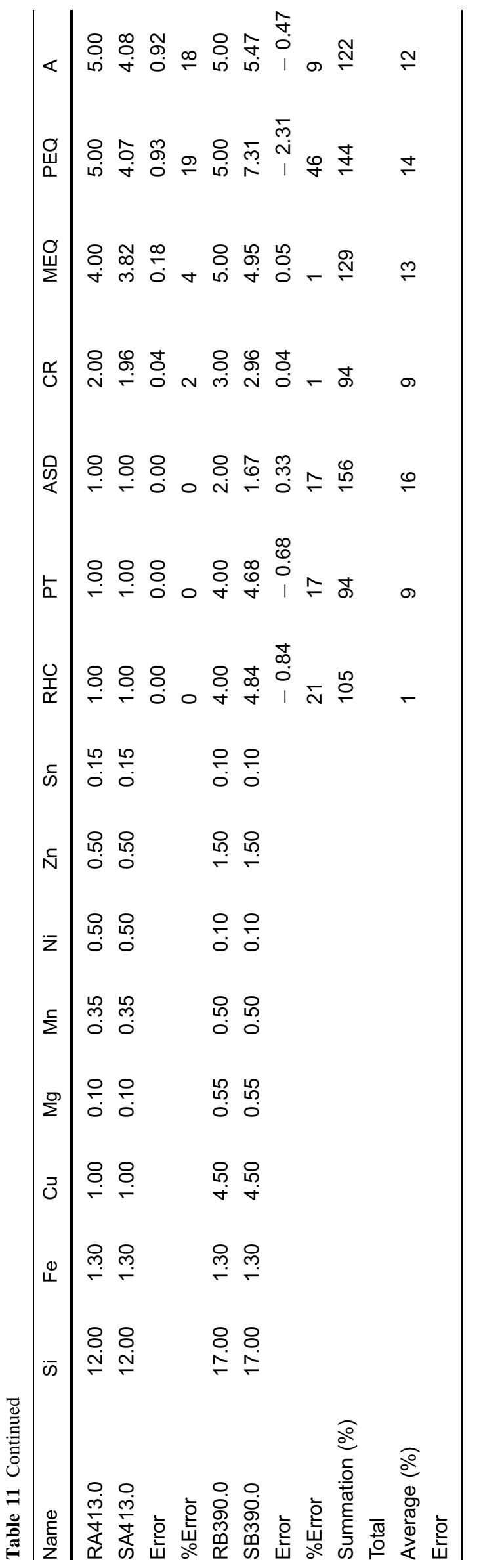

- Anodizing (A) Characteristic that measures the clarity of color, gloss and uniformity of the transparent anodized coating applied by means of a sulfuric acid electrolyte.

\section{Error and Accuracy of the Model \\ Mechanical Properties}

As shown in the properties that present the highest accuracy are impacted strength, impact fatigue and ultimate tensile strength with an accuracy of over $95 \%$ in all. On the other hand, the characteristics that present less precision in the model for the mechanical properties are elongation, the Young's modulus and the deformation stress. The accuracy of these is above $86 \%$ in the case of elongation. The other two characteristics have an accuracy over $90 \%$ (as can be seen in Table 9), which establishes that the model is accurate and meets the essential elements for a rapid approximation of the behavior of the alloys.

It is important to note that the simulation of these characteristics, in particular, is useful for establishing the performance of the alloys used in the casting industry under pressure and therefore reduces the work, the resources used for its elaboration and the possibility of risk in the timely calculation of these properties.

\section{Physical Properties}

For the simulation of the physical properties of the alloys, we used a set of equations that established the specific behavior of each element. These forecasts showed a great accuracy as shown in Table 10, where it is observed that the calculation of the density, the melting range and the coefficient of thermal expansion show a high accuracy above $95 \%$ of reliability in the prognosis. While properties such as thermal and electrical conductivity present an accuracy of $90 \%$ each, increasing the reliability in this part of the model.

The analysis of these properties is interesting from the manufacturer view, since in the cast iron industry, the melting range and the thermal conductivity play a significant role in establishing the ideal melting and injection temperature of the material.

\section{Specific Properties of Die Casting}

Within the specific properties, one of the most important is the corrosion resistance of the material. In this sense, the designed model establishes this characteristic according to the properties quoted by NADCA, with accuracy greater than $90 \%$ as seen in Table 11, making it a reliable forecast for this particular property. 
Other properties of particular importance to the die casting industry are the filling capacity and the tendency of the alloy to adhere, which play an important role during the die casting process. Accordingly, the evaluation and modifications necessary for the operation and control of the process are made. The built-in forecast model allows these adjustments before the pre-production stage with a reliability of both factors above $80 \%$ as seen in Table 11 . This provides an advantage for the industry, reducing the preproduction costs considerably by giving operators the possibility of establishing basic adjustments in the process, without the larger expenses in their preparation.

In addition, the characteristics such as ease and quality of machining, ease and polish quality, ease and quality of electroplating and anodizing, although they are no longer part of the process of die casting are part of the subsequent processes, which give the finished product, with a reliability greater than $85 \%$ (as seen in Table 11). While it is necessary to plan and control the final characteristics of the product, to improve its particularities during the mass production process, with these it is possible to obtain reliable, stable and economic processes that provide a competitive advantage within the industrial sector.

Pressure resistance, for the general industry, is significant in the design of many products for the electrical, automotive and appliance industries, as well as for the design of safe household use products. The model allows establishing this property with reliability above 9\% (see Table 11).

\section{Validation of Model Through an External Alloy}

The aluminum matrix composite alloys (MMC) are aluminum-based alloys reinforced with up to $20 \%$ silicon carbide. These alloys are used in die casting for high-performance components.

Table 12. Chemical Characteristics of the MMC Family

\begin{tabular}{ll}
\hline Element & Range \\
\hline Silicon & $9.50-10.50$ \\
Iron & $0.8-1.20$ \\
Copper & 0.20 max \\
Magnesium & $0.50-0.70$ \\
Manganese & $0.50-0.80$ \\
Nickel & 0.5 \\
Titanium & 0.20 max \\
Zinc & 0.05 max \\
Total others & 0.10 total \\
& 0.03 max \\
Aluminum & Balance \\
\hline
\end{tabular}

This family of alloys have characteristics similar to those that are used as the basis for the run of the model (Table 12). However, they present some significant differences such as the percentages of nickel, zinc and copper which are far from the database. Therefore, when making the forecast of the properties of this alloy, an adjustment will have to be made to consider these changes in alloy percentages.

The F3N.10S-F alloy which has the following chemical characteristics will be taken as reference from the MMC family:

The estimation of the model can be seen in Table 13, when testing the model with the data of the MMC family.

For the estimation of $\mathrm{H}, \mathrm{E}, \mathrm{PEQ}$, a change was made in the parameters of the model, to simulate them by means of a multilinear regression that takes as base elements, nickel, copper, manganese and iron.

In the case of YS, YM, CR and MEQ, their errors were 50, 45,35 and $33 \%$. This is because the predominant elements for these properties are nickel, copper and zinc, which are found outside the parameters of the family of alloys that were used as a basis for the calculation of the model and which present errors in the calculation.

Finally, as can be seen, the model can be used in families of alloys near the original base, with an acceptable degree of accuracy. However, as mentioned in the previous sections, it is possible to make it more precise if the base of the forecast is nearby families of alloys.

\section{Conclusions and Discussion}

The model presented in this article showed an accuracy level higher than $90 \%$ when characterizing alloys, allowing it to be used as a fast and reliable approximation method to predict the specific characteristics of the alloyed material. In this way, product designers will be able to select the characteristics of the material based on its chemical composition and thus determine the different physical, mechanical and specific properties of the material. This allows the selection of the most important properties according to the industrial necessity. For example, if the product is to be subjected to extreme environmental conditions such as humidity, rainfall or will be near coastal areas, the designer will need a corrosion-resistant alloy and if possible will avoid painting processes to reduce cost and environmental impact.

Also, it can be seen that the model is able to predict with great precision alloys that are outside the base family with which the model is fed. However, these must be formulated in a manner close to the base family. This can be observed 
Table 13. Evaluation of the Model for the F30n.10S-F Alloy, Where S Represents the Simulated Alloy and R the Real Alloy

\begin{tabular}{lrlllllllllll}
\hline Characteristic & UTS & E & H & D & MR & CTE & TC & RHC & PT & ASD & PEQ & A \\
\hline R.F30n.10S-F & 310 & 0.9 & 56 & 2.65 & 575 & 21.4 & 161 & 1 & 2 & 2 & 5 & 4 \\
S.F30n.10S-F & 308 & 0.8 & 57.66 & 3 & 579 & 21 & 184 & 1.61 & 2 & 1.66 & 4.40 & 3.38 \\
Error & 2 & 0.1 & 1.66 & 0.35 & 4 & 0.4 & 23 & 0 & 0 & 0.34 & 0.6 & 0.62 \\
\%Error & 1 & 11 & 3 & 13 & 1 & 2 & 14 & 0 & 0 & 17 & 12 & 16 \\
\hline
\end{tabular}

in MMC alloys, and it is also necessary to consider that those elements that are outside the parameters fixed by the base alloys may present a considerable error as in the case of YS, YM, CR and MEQ. Consequently, in the future it will be possible to develop other alternatives for the modeling of these conditions, such as dynamic modeling or neural networks that allow greater precision and prediction for greater number of alloys with very different chemical characteristics. With respect to the development of the presented model, it will be used to formulate a series of alloys that are die castable and resistant to corrosion with which to reduce the painting processes in the manufacture of injected parts.

Finally, the model can also be employed for the analysis of various alloys through simulation, using basic data such as the chemical composition of the alloy. In that way, the most promising alloys can be selected and tested with them, considerably reducing the time and costs of traditional trial-and-error processes.

\section{Open Access}

This article is distributed under the terms of the Creative Commons Attribution 4.0 International License (http://creativecommons.org/licenses/by/4.0/), which permits unrestricted use, distribution, and reproduction in any medium, provided you give appropriate credit to the original author(s) and the source, provide a link to the Creative Commons license, and indicate if changes were made.

\section{REFERENCES}

1. K. Albe, P. Erhart, M. Müller, Analytic interatomic potentials for atomic-scale simulations of metals and metal compounds: a brief overview, in Integral Materials Modeling: Towards Physics-Based Through-Process Models, ed. by G. Gottstein (Wiley, New York, 2007), p. 197-206

2. S. Bagherifard, I. Fernandez-Pariente, R. Ghelichi, M. Guagliano, Effect of severe shot peening on microstructure and fatigue strength of cast iron. Int. J. Fatigue 65, 64-70 (2014)
3. C. Beckermann, Modelling of macrosegregation: applications and future needs. Int. Mater. Rev. 47(5), 243-261 (2002)

4. S. Biswas, C. Monroe, T. Prucha, Use of published experimental results to validate approaches to gray and ductile iron mechanical properties prediction. Int. J. Met. 11(4), 656-674 (2017)

5. O. Boydak, M. Savas, B. Ekici, A numerical and an experimental investigation of a high-pressuredie-casting aluminum alloy. Int. J. Met. 10(1), 56-69 (2015)

6. J. Campbell, Complete Casting Handbook, 2nd edn. (Elsevier Butterworth-Heinemann, Oxford, 2015)

7. L. Chen, J. Peng, J. Xu, H. Choi, C. Li, Achieving uniform distribution and dispersion of a high percentage of nanoparticles in metal matrix nanocomposites by solidification processing. Scr. Mater. 69(8), 634-637 (2013)

8. M. Ciaccia, G. Aparicio, R. Tinedo, G.D.H. Potenza, Ajuste de la ecuación de rasmussen para las aleaciones de aluminio 2024, 3003, 6061 y 6063. In: 8 Congreso Iberoamericano de Ingeniería Mecánica (2007)

9. E. Cinkilic, W. Sun, D. Klarner, A. Luo, Use of calphad modeling in controlling the microstructure of cast aluminum alloys, in American Foundation Society Transactions, pp. 57-61 (2015)

10. P. Coloma, U. Izagirre, J. Jorcin, N. Lapea, Chromium-free conversion coatings based on inorganic salts $(\mathrm{zr} / \mathrm{ti} / \mathrm{mn} / \mathrm{mo})$ for aluminum alloys used in aircraft applications. Appl. Surf. Sci. 345(1), 24-35 (2015)

11. T. Dursun, C. Soutis, Recent developments in advanced aircraft aluminium alloys. Mater. Des. 1980-2015(56), 862-871 (2014)

12. D. Ghaffari, M. Worswick, U. Ali, M. Gharghouri, Mechanical response of az31b magnesium alloy: experimental characterization and material modeling considering proportional loading at room temperature. Int. J. Plast. 55, 247-267 (2014)

13. J. Guo, S. Zhao, R. Murakami, R. Ding, S. Fan, Modeling the hot deformation behavior of al alloy 3003. J. Alloys Comp. 566, 62-67 (2013)

14. Y. Hangai, H. Kamada, T. Utsunomiya, S. Kitahara, O. Kuwazuru, N. Yoshikawa, Aluminum alloy foam core sandwich panels fabricated from die casting aluminum alloy by friction stir welding route. J. Mater. Process. Technol. 214(9), 1928-1934 (2014) 
15. A. Hu, J. Cai, L. Sun, H. Jiang, Y. Sang, T. Liu, Diecasting simulation and process optimization of an a356 aluminum alloy polishing plate. Int. J. Met. 10(3), 315-321 (2016)

16. I. Ito, T. Mizuguchi, in Proceedings of International Conference on Material Science and Engineering 2016, chap. Metals. Alloys and Composite Materials, pp. 21-26. Scientific (2016)

17. L. Katgerman, A mathematical model for hot cracking of aluminium alloys during D.C. casting, in Essential Readings in Light Metals, ed. by J.F. Grandfield, D. G. Eskin (Springer, Berlin, 2016), vol. 3, 907-911.

18. K. Kikuya, M. Ueda, H. Yamamoto, Cathode materials: LiNiO2 and related compounds, in Lithium-Ion Batteries (Springer, New York, 2009), pp. 315-321.

19. D. Koli, G. Agnihotri, R. Purohit, Advanced aluminium matrix composites: the critical need of automotive and aerospace engineering fields. Mater. Today Proc. 2(4), 3032-3041 (2015)

20. R. Lewis, K. Ravindran, Finite element simulation of metal casting. Numer. Methods Eng. 47(1), 29-59 (2000)

21. Z. Ling, Y. Li, Z. Luo, Y. Feng, Z. Wang, Resistance element welding of 6061 aluminum alloy to uncoated 22 mnmob boron steel. Mater. Manuf. Process. 31(6), 2174-2180 (2016)

22. L. Liu, S.K. Feng, F.Z. Yang, W.G. Zhang, Z.J. Liu, High temperature rupture life of nickel-based superalloy under directional solidification with high temperature gradient, in IUMRS International Conference in Asia, Materials Science Forum (Trans Tech Publications, 2017), vol. 898, pp. 422-429.

http://doi.org/10.4028/www.scientific.net/ MSF.898.422

23. NADCA: Product Specification Standards for Die Casting, 9 edn. North American Die Casting Association (2015)

24. L. Nastac, N. El-Kaddah, Microstructure evolution of cast $\mathrm{mg}$ az31b alloy at low superheat. Int J Met 7, 39-48 (2013)

25. M. Paradis, H. Abdelaziz, W. Doty, H. Samuel, On the mechanical properties of lost foam cast a356 automotive components: effects of melt treatment and solidification conditions. Int J Met 11(3), 494-505 (2017)

26. K. Rassmussen, Full-range stressstrain curves for stainless steel alloys. J. Constr. Steel Res. 59(1), 47-61 (2003)

27. A. Sabau, S. Viswanathan, Microporosity prediction in aluminum alloy castings. Metal. Mater. Trans. B 33(2), 243-255 (2002)
28. J. Shackelford, Y. Han, S. Kim, S. Kwon, in CRC Materials Science and Engineering Handbook (CRC Press, 2016), 4th edn. https://books.google.com.mx/ books?id=rtaYCgAAQBAJ

29. A. Shokuhfar, O. Nejadseyfi, A comparison of the effects of severe plastic deformation and heat treatment on the tensile properties and impact toughness of aluminum alloy 6061. Mater. Sci. Eng. A 594, 140-148 (2014)

30. G. Sigworth, Fundamentals of solidification in aluminium castings. Int. J. Met. 8(1), 7-20 (2014)

31. D. Stefanescu, Science and Engineering of Casting Solidification, 2nd edn. (Springer, US, 2009)

32. E. Suyitno, V. Savran, L. Katgerman, Effects of alloy composition and casting speed on structure formation and hot tearing during direct-chill casting of $\mathrm{Al}-\mathrm{Cu}$ alloys. Metall. Mater. Trans. Phys. Metal. Mater. Sci. 35(11), 3551-3561 (2004)

33. A. Tronche, L. Greer, Design of grain refiners for aluminium alloys, in Essential Readings in Light Metals, ed. by J.F. Grandfield, D.G. Eskin (Springer, Cham, 2016)

34. K. Velmanirajan, K. Anuradha, A. Abu, R. Narayanasamy, R. Madhavan, S. Satyam, Experimental investigation of forming limit, void coalescence and crystallographic textures of aluminum alloy 8011 sheet annealed at various temperatures. Arch. Civil Mech. Eng. 14(3), 398-416 (2014)

35. W. Volksen, K. Lionti, T. Magbitang, G. Dubois, Hybrid low dielectric constant thin films for microelectronics. Scr. Mater. 74, 19-24 (2014)

36. L. Wang, D. Apelian, M. Makhlouf, B. aluminum die casting alloys. Tech. rep., Defense Logistic Agency

37. Y. Wang, F. Fan, S. Lin, Experimental investigation on the stability of aluminium alloy 6082 circular tubes in axial compression. Thin Walled Struct 89, 54-66 (2015)

38. L. Zhang, L. Li, H. Ju, B. Zhu, Inverse identification of interfacial heat transfer coefficient between the casting and metal mold using neural network. Energy Convers. Manag. 51(10), 1898-1904 (2010)

39. Y. Zhang, T. Zuo, Z. Thang, M. Gao, K. Dahmen, P. Liaw, Z. Lu, Microstructures and properties of highentropy alloys. Progr. Mater. Sci. 61, 1-93 (2014)

40. M. Zhou, Y. Lin, J. Deng, Y. Jiang, Hot tensile deformation behaviors and constitutive model of an alznmgcu alloy. Mater. Des. 59, 141-150 (2014) 